\title{
CURSO DE FORMAÇ̃̃O DE PROFESSORES (AS) POR MEIO DO PROGRAMA EDUCAÇÃ O SEXUAL EM DEBATE NA RÁDIO UDESC FM 100.1 FLORIANÓPOLIS: ALGUMAS REFLEXÕES SOBRE OS CAMINHOS PERCORRIDOS
}

\author{
CURSO DE FORMACIÓN E PROFESORES POR MEDIO DEL PROGRAMA \\ EDUCACIÓN SEXUAL EN DEBATE EN RADIO UDESC FM 100.1 \\ FLORIANÓPOLIS: ALGUMAS REFLEXIONES SOBRE LOS CAMINOS \\ RECORRIDOS
}

TRAINING COURSE OF TEACHERS THROUGH THE PROGRAM SEXUAL EDUCATION IN DEBATE IN THE RADIO UDESC FM 100.1 FLORIANÓPOLIS: SOME REFLECTIONS ON THE PERCORRATED WAYS

\author{
Márcia de FREITAS ${ }^{1}$ \\ Sonia Maria Martins de MELO $^{2}$ \\ Aline Silva ZILLI ${ }^{3}$ \\ Andréia Valéria de Souza MIRANDA ${ }^{4}$
}

RESUMO: Este artigo propõe reflexões sobre um processo de criação coletiva, que
teve como resultado final a proposta de um projeto de curso de extensão, objetivando
ser mais um meio de sensibilização e ampliação do conhecimento e das discussões
acerca da temática educação sexual emancipatória. Por meio de programas de rádio, o
curso ocupará o espaço correspondente a quatro programas na Rádio UDESC FM
100.1, dentro de um espaço semanal existente há 8 anos na programação, denominado
Educação Sexual em Debate. A estrutura destes programas atende aos pressupostos do
Programa de Extensão Formação de Educadores em Educação Sexual: interface com as
tecnologias- do grupo EDUSEX -, e que tem o intuito de possibilitar aos ouvintes
momentos de sensibilização para a possibilidade de vivências de uma educação sexual
emancipatória. O curso tem a intenção de atingir pessoas interessadas na temática da
educação sexual e compromete-se em discutir a diferenciação de sexo e sexualidade, a
educação sexual na perspectiva emancipatória, a declaração do direitos sexuais como
direitos universais e o direito à educação sexual compreensiva na infância e

${ }^{1}$ Doutoranda do Programa de Pós-Graduação em Educação/PPGE/ Universidade do Estado de Santa Catarina/UDESC, Supervisora Escolar da Prefeitura Municipal de Florianópolis, Membro do grupo de pesquisa EDUSEX Formação de Educadores e Educação Sexual CNPq/UDESC e autora do projeto de pesquisa em andamento. Email: pedagodamarciareitas@gmail.com

${ }^{2}$ Doutora em educação e docente no Departamento de Pedagogia e no Programa de Pós-Graduação em Educação/PPGE/UDESC, Líder do Grupo de Pesquisa Formação de Educadores e Educação Sexual $\mathrm{CNPq} / \mathrm{UDESC}$. Orientadora do projeto de pesquisa em andamento. Email: soniademelo@gmail.com

${ }^{3}$ Mestranda do Programa de Pós-Graduação em Educação/PPGE/ Universidade do Estado de Santa Catarina/UDESC, Professora de Língua Portuguesa da Prefeitura Municipal de Florianópolis, Membro do grupo de pesquisa EDUSEX Formação de Educadores e Educação Sexual CNPq/UDESC e autora do projeto de pesquisa em andamento. Email: alinezilli81@ gmail.com

${ }^{4}$ Doutoranda do Programa de Pós-Graduação em Educação/PPGE/ Universidade do Estado de Santa Catarina/UDESC, Enfermeira da Prefeitura Municipal de Lages, Membro do grupo de pesquisa EDUSEX Formação de Educadores e Educação Sexual CNPq/UDESC e autora do projeto de pesquisa em andamento. Email: andreiavaleriamiranda@hotmail.com 
adolescência. Instigar e ampliar essas discussões são caminhos a serem percorridos neste projeto.

PALAVRAS-CHAVE: Educação Sexual. Curso de extensão para formação de professores (as). Programa de rádio.

RESUMEN: En este artículo se plantean reflexiones sobre el proceso colectivo creativo que tenía como resultado final la propuesta de un proyecto de extensión, con el objetivo de ser un medio alternativo de sensibilización y ampliación de los conocimientos y las discusiones sobre el tema de la educación sexual emancipatoria. A través de programas de radio, el curso va a ocupar el espacio que corresponde a cuatro programas en la UDESC radio FM 100.1, en un horario semanal que ha tenido lugar durante ocho años, llamado Debatiendo la Educación Sexual. La estructura de estos programas está de acuerdo con las presuposiciones del Programa de Formación Extensión de Educadores en Educación Sexual: interfaz con las tecnologías - del grupo EDUSEX - que tiene el objetivo de proporcionar a los oyentes momentos de sensibilización a la posibilidad de experiencias de una educación sexual emancipadora. El curso tiene la intención de llegar a las personas interesadas en el tema de la educación sexual y se compromete a discutir la diferenciación entre el sexo y la sexualidad, la educación sexual en la perspectiva emancipatoria, la declaración de los derechos sexuales como derechos universales y el derecho a una educación sexual integral durante la infancia y la adolescencia. Instigar y ampliar estas discusiones son caminos que serán atravesados en este proyecto.

PALABRAS CLAVE: Educación sexual. Curso de extensión para la formación de maestros (as). Programa de radio.

ABSTRACT: This article brings up reflections on a collective creative process, which had as a final result the proposal of an extension course project, with the objective of being an alternative mean of awareness and broadening of knowledge and discussions about the subject of emancipatory sexual education. Through radio programs, the course will occupy a space that corresponds to four programs on UDESC Radio FM 100.1, in a weekly schedule that has been taking place for 8 years, called Debating Sex Education. The structure of these programs meets the presuppositions of the Sex Educators Formation Extension Program: interface with technologies - from the EDUSEX group -, which has the aim of providing to the hearers moments of awareness to the possibility of experiences of an emancipatory sex education. The course has the intent of reaching people interested in the subject of sex education and is committed to discussing the differentiation between sex and sexuality, sex education under an emancipatory perspective, the declaration of sex rights as universal rights and the right to a comprehensive sex education during infancy and adolescence. To instigate and broaden these discussions are paths to be gone through in this project.

KEYWORDS: Sex Education. Extension course for the formatio of teachers. Radio program. 


\section{Introdução}

Neste artigo traremos algumas reflexões sobre os caminhos percorridos em uma proposta de curso de extensão para formação de professores(as). Para iniciarmos as discussões, vamos contextualizar de onde surgiu esta proposta. Por meio do Grupo de Pesquisa EDUSEX - Formação de Educadores e Educação Sexual, existente há 30 anos, na Universidade do Estado de Santa Catarina/UDESC - fomos conhecendo a atuação integradamente em pesquisa, ensino e extensão na área da educação sexual emancipatória, sobre a qual trataremos mais adiante. Este Grupo tem inserção nos processos de formação regular de profissionais de educação no curso de Pedagogia, nas modalidades presencial e a distância, e no Curso de Pós-Graduação em Educação (Mestrado e Doutorado). Na pós graduação é oferecida a disciplina denominada Tecnologia e formação de educadores: interfaces com a temática educação sexual, pela professora Dr ${ }^{a}$ Sonia Maria Martins de Melo, líder do referido Grupo de Pesquisa, docente permanente do PPGE-UDESC. As vagas para a disciplina são oferecidas em primeiro momento para os alunos/alunas regulares da Pós-Graduação e as vagas que não forem preenchidas são abertas posteriormente para a comunidade, onde tem preponderado a participação de professores e professoras oriundos de escolas públicas.

O Grupo EDUSEX atua também em projetos de extensão com várias ações, dentre elas o Programa de Rádio Educação Sexual em Debate, existente regularmente há quase nove anos na Rádio UDESC FM 100.1- Florianópolis. Sua principal característica é de ser um programa semanal, ao vivo, de entrevistas com pesquisadores nacionais e internacionais e demais educadores que tratem de temas correlatos à temática das interfaces entre educação e sexualidade. Como a equipe do Grupo EDUSEX é a idealizadora e realizadora do programa, planeja e escolhe os temas dessas entrevistas, que são disponibilizadas pelas ondas da rádio UDESC, tendo como objetivo sensibilizar educadores e educadoras para a temática por meio de formação intencional, em uma vertente emancipatória de educação sexual. Até a produção desse texto mais de 220 programas já foram realizados ao vivo semanalmente, nas sextas feiras pela manhã, gravados, reprisados também semanalmente nas quartas feiras a noite, como horário alternativo, bem como disponibilizados gratuitamente em vários espaços de acesso, atualmente também na página no facebook do programa, para uso como material de apoio à formação de educadores e educadoras. Assim, cada um pode utilizar os programas da melhor maneira que lhe prouver para atender suas reais necessidades. 
A partir desse contexto, como trabalho final da disciplina Tecnologia e formação de educadores: interfaces com a temática educação sexual, em 2015/1, do PPGEUDESC, fomos desafiadas pela professora a criarmos uma proposta de um curso de extensão para ser vivenciado no espaço do Programa Educação Sexual em Debate, com a temática educação sexual na vertente emancipatória. É importante salientar que entendemos Educação Sexual Emancipatória como a busca de um entendimento amplo de sexualidade, sem ser baseado em uma reprodução do que está posto, mas repensando esta temática de maneira crítica, partindo de uma reflexão acerca das abordagens sobre a sexualidade e os consequentes processos de educação sexual daí resultantes, entendidos como uma construção sócio histórica, fruto das relações sociais entre os seres humanos no mundo, ao produzirem suas vidas.

\section{Formação de professores(as) em educação sexual emancipatória}

A partir do exposto, ao repensar a formação de professores e professoras e demais pessoas interessadas na temática, usando várias ferramentas midiáticas (KENSKI, 2007), dentre elas o rádio, elaboramos então uma proposta de um curso sobre educação sexual via Rádio UDESC/ FM 100.1-Florianópolis, entendendo ser esse mais um meio possibilitador de momentos em que profissionais da educação e demais pessoas interessadas possam refletir sobre os paradigmas construídos em relação à sexualidade e seus reflexos em nossas vidas.

Assim sendo, via esse curso organizado intencionalmente em seus objetivos, etapas e temas, pensamos ampliar o uso do programa de rádio já existente, com mais um desafio: o de uma proposta de curso de sensibilização dos ouvintes para a possibilidade de construção de práticas pedagógicas emancipatórias no dia-a-dia de diversos contextos educativos, dentre eles as escolas. Isto porque Pacheco (2014) nos alerta sobre a importância das relações estabelecidas nas instituições escolares:

A escola é um espaço privilegiado nas suas trocas e significações no que se refere à relação estabelecida entre as crianças e as mídias. Portanto, cabe pensar que nesse relacionamento das pessoas com o mundo de uma forma dialógica, também se deve pensar no uso das diferentes linguagens midiáticas para uma formação reflexiva e crítica. Nossas práticas pedagógicas, por mais que mudemos as ferramentas, por vezes repetem modelos ultrapassados. (p.119) 
Durante a disciplina dialogamos com alguns autores e autoras que nos proporcionaram ricos momentos de leitura e reflexão sobre a história, vertentes e construção de paradigmas pedagógicos a respeito da sexualidade humana, bem como fomos aprofundando os temas por meio de debates que foram surgindo no decorrer das aulas, com os relatos do cotidiano de profissionais de diversas instituições educativas que compunham a turma.

Nesta etapa ficou evidenciado o quanto é difícil ainda para algumas pessoas, dentre elas profissionais da educação em vários tipos de organizações educativas, falar sobre essa temática e mesmo entender que o calar-se sobre ela ajuda a compor o currículo oculto muitas vezes desumano e repressor. Podemos, portanto, compreender os espaços educativos escolares como parte viva do processo de educação, sempre também sexual, já que esse é um processo permanente que acontece nas relações sociais entre as pessoas.

Mas ainda hoje, muitas vezes, ao se pensar a sexualidade humana, percebemos que ela ainda é tratada por vários segmentos dos grupos sociais de maneira repressora, alienante, causando o estranhamento do ser humano em relação a essa sua dimensão, mesmo não tendo como separá-la da nossa existência. Essa maneira de lidar com a sexualidade, parte fundamental dos motivos que nos levaram a estruturar e propor a construção do curso via Rádio UDESC, no espaço de 4 semanas do programa Educação Sexual em Debate, pode e deve nos desafiar para que possamos buscar melhor compreender criticamente os modos de pensar sobre essa rica dimensão humana. Melo e Pocovi (2002) salientam que:

Cada grupo social constrói e recria imaginários sociais e particulares sobre a sexualidade, realizadas por um grupo social, e suas expressões no cotidiano maior das relações sociais dos seres humanos ao produzirem suas vidas: é o que podemos chamar de seus paradigmas sobre educação sexual. (p. 31)

Partem as autoras portanto do entendimento que somos todos seres sexuados e estamos sempre em processo de educação, sendo que, a partir dessa forma de perceber e compreender o mundo, na proposta do curso estaremos constantemente nos educando sexualmente numa perspectiva emancipatória.

Educação sexual é ainda tema muito controverso nas sociedades contemporâneas, por várias razões que não são foco destas reflexões, mas só as existências dessas controvérsias reafirmam e justificam a necessidade de refletirmos 
sobre as possibilidades de nos educarmos intencionalmente sobre educação sexual numa perspectiva de emancipação, nesses caso portanto com apoio inclusive de um curso via rádio.

Isto porque, pelo último censo do $\mathrm{IBGE}^{5}$, quase 47 milhões de lares brasileiros tem no rádio um instrumento de informação e comunicação. Portanto, o curso inserido no programa Educação Sexual em Debate buscará oferecer mais um espaço potencializador para a sensibilização dos ouvintes sobre educação sexual emancipatória, na forma de uma ação de extensão programada e feita via ondas de uma rádio educativa, numa perspectiva de auxiliar inclusive numa formação continuada para professores, professoras e demais interessados na temática.

Com o intuito de elucidar o conceito de formação continuada, que pode ser realizado via este curso, vamos nos apoiar em Figueiró (2014), para quem o termo formação e, no caso em questão, a formação do/da professor/professora, engloba tanto a formação inicial quanto a continuada. A primeira, conforme Figueiró, pode ser entendida antes até do ingresso em curso de formação inicial, pois o ser humano vai construindo suas representações sociais ao longo da sua trajetória de vida. Portanto, as experiências de vida da pessoa interferem na sua formação como professor/professora. A autora resume esse entendimento em seu livro citando Giovanni, conforme abaixo:

[...] são momentos igualmente formadores de profissional em ensino: a história de vida, as experiências e os contextos que antecederam a escolha da profissão, os cursos de formação inicial, as ações de formação continuada, os diferentes momentos de exercício da profissão e, finalmente as condições e os contextos nos quais tais momentos efetivam (GIOVANNI, 1998 apud FIGUEIRÓ, 2014, p.105).

Mas a profissão de professor/professora preconiza uma formação continuada, ou seja, as propostas ou ações pensadas e planejadas, em um primeiro momento para aprimorar a prática pedagógica do professor/professora, tem o objetivo de contribuir para o desenvolvimento destes/dessas profissionais, que criam e constroem conhecimentos, estabelecendo relações com seus alunos/alunas no dia a dia - onde são abordados os mais diversos assuntos - aí incluída a questão da educação sexual, exigindo assim uma formação constante, num movimento de autorreflexão, como relata Figueiró (2014):

${ }^{5}$ Instituto Brasileiro de Geografia e Estatística. Vamos conhecer o Brasil. 2010. Disponível em: <http://7a12.ibge.gov.br/vamos-conhecer-o-brasil/nosso-povo/familias-e-domicilios〉. Acesso em: 30 mar. 2015. 
Durante a formação inicial, o exercício da autorreflexão ou mais propriamente da reflexão sobre a prática pedagógica fica limitado. É após estarem inseridos na prática profissional deparando-se com possibilidades e limites seus, dos seus alunos e do contexto educacional como um todo, em nível micro e macro institucional, que os professores poderão exercitar a reflexão. (p.102).

A formação continuada deve ser focada em situações reais que os/as professores/as vivenciam em sala de aula, pois, para que ela seja bem-sucedida, os/as docentes devem estar envolvidos no processo de formação, para ajudá-los a buscarem soluções para seus problemas. A autora também se apoia em Alarcão (1998), para explicar os pressupostos em que a formação continuada deve estar pautada para que se efetive. O primeiro pressuposto citado é que o professor/professora seja considerada/o sujeito de sua maneira de ser e agir profissionalmente, e a realidade desses/dessas profissionais devem ser elementos significativos para o processo de formação continuada. O segundo pressuposto, é que haja suporte para o/a professor/professora, enquanto do/da formador/formadora se espera que o/a mesmo/mesma assuma o papel de facilitar e mobilizar a formação. O terceiro e último pressuposto se refere à importância de considerar a escola como objeto de reflexão e como local onde acontecem as ações no dia a dia. O/a professor/professora tem que ser compreendido/compreendida como um alguém que produz conhecimento, saberes e não apenas um transmissor.

O momento de formação continuada pode ser pensado e planejado de uma maneira que permita um tempo para que o professor(a) possa repensar sua prática pedagógica, levando as reflexões levantadas para sua prática e discutidas com o grupo. Essa vai ser uma das bases do oferecimento do curso pela rádio. Assim, os intervalos entre o oferecimento das etapas semanais do curso permitirão que sejam dadas aos cursistas orientações sobre momentos de reflexões, a serem feitas pelos mesmos, por meio de texto escrito e enviado por e-mail, ao-a docente do curso.

Concordamos com Pacheco (2014) quando reafirma, em sua dissertação de mestrado, a importância da formação continuada, já que esta pode estimular a compreensão crítica de professoras/professores. Quando nos referimos à formação no que tange a temática da sexualidade, esta se faz necessária continuamente porque currículos escolares - nos quais se relacionam docentes e crianças - são plenos de sexualidade, mesmo que na maioria das vezes essa dimensão estar oculta ou negada, porque são propostos e vivenciados por e para pessoas, sempre sexuadas. 
Para a formação de professores/professoras, podemos utilizar metodologias e recursos variados, para que possamos alcançar os diversos perfis de profissionais em múltiplos lugares, pensando em uma formação que atenda a diversidade de perfis dos ouvintes de uma rádio educativa. A utilização do rádio dentre as várias ferramentas midiáticas é um dos recursos que podemos utilizar para alcançar esses/essas profissionais. Hoje percebemos como as tecnologias são importantes para a educação, mas é importante salientar que não basta ter acesso a elas, se faz necessário saber utilizá-las na perspectiva de que atendam a necessidade dos usuários.

\section{Projeto de curso de extensão via Rádio UDESC FM 100.1 Florianópolis}

Após muitas leituras e reflexões sobre essas interfaces acima registradas, iniciamos o processo de criação do projeto de um curso extensão. No primeiro momento chegamos ao entendimento de como o curso seria organizado: a começar pelo título "Formação continuada intencional em educação sexual emancipatória, por meio da Rádio UDESC FM 100.1 Florianópolis”. O público alvo dessa formação poderá ser formado de ouvintes do programa semanal, pessoas interessadas na temática de educação sexual, que podem ser profissionais da educação, discentes de vários níveis de ensino, outros membros de comunidades escolares, profissionais da saúde, membros de vários tipos de famílias, enfim, da comunidade em geral. Todos aqueles que, ouvindo o convite nas semanas anteriores pela rádio, se tornarão ouvintes intencionais do curso nos dias de sua execução. Nosso intuito é que esta recepção seja demonstrada por meio do correio eletrônico e, assim, o participante interessado que se comunicar com a equipe receberá o questionário daquela etapa por e-mail e o enviará preenchido ao endereço disponibilizado pelo curso. Será considerado então participante legitimado do curso, com direito ao certificado de extensão, o ouvinte que completar os quatro módulos do curso, ouvindo o programa em tempo real, nas reprises ou assistindo às gravações disponíveis na página do programa no facebook, estudando os temas, respondendo e enviando os questionários preenchidos.

O curso será realizado em quatro módulos, ou seja, quatro programas, intervalados com tempo para leituras e reflexões críticas dos ouvintes, por meio de respostas aos questionários devidos, sobre o tema apresentado em cada etapa. Terá carga horária total de 10 horas, sendo que esta carga horária será composta pelas duas 
horas expressas pelos quatro programas de rádio, com 30 minutos de duração cada, mais as oito horas do tempo de leituras exigidas para complementar as reflexões e responder aos questionários. A certificação será emitida somente no final do curso, sendo que os participantes com no mínimo $75 \%$ de participação nos envios dos questionários receberão o certificado. A apresentação do programa ficará ao cargo de um docente ligado ao Grupo EDUSEX.

O primeiro módulo do curso, programa 1, terá roteiro explicitando a estrutura do mesmo: módulos, período, critério e formas de avaliação e carga horária. Ainda no primeiro módulo, além de explicar sobre a organização do curso, será feita uma introdução temática, conversando sobre o porquê ficamos inibidos diante do tema sexualidade, com enfoque no que é sexo e o que é sexualidade, na busca da compreensão de que somos pessoas sexuadas, queiramos ou não, saibamos ou não, e que sempre estamos nos educando sexualmente uns aos outros.

No segundo módulo, programa 2, será abordado o que é educação sexual e o que é educação sexual na perspectiva emancipatória. Este módulo parte do princípio que somos sempre educados sexualmente de maneira informal, na família, na rua, nos bares, nos cinemas, nos shoppings, nas igrejas, nas escolas, enfim, em todos os lugares onde existe vida humana, existem relações sociais sempre entre pessoas sexuadas para serem apreendidas, trocadas, usufruídas ou ignoradas. A educação sexual informal é muito forte também na mídia e em várias publicações. A educação sexual emancipatória pressupõe um trabalho educativo intencional comprometido em promover a autonomia do educando, buscando superar padrões de comportamentos hierarquizados e estereotipados, superando preconceitos e tabus por meio da compreensão dos aspectos sócio-históricos-políticos que influenciaram na construção dos mesmos. O objetivo desse módulo é oportunizar aos participantes a reflexão sobre as possibilidades de uma perspectiva emancipatória da educação sexual.

Já no terceiro módulo abordaremos a Declaração dos Direitos Sexuais como Direitos Humanos Universais, na versão aprovada na Espanha em Valência em 1997, no XIII Congresso Mundial de Sexologia, coordenado pela WAS, World Association of Sexology e encontrada em Melo e Pocovi (2002). Ela lista princípios em que constam, com muita propriedade, os direitos básicos de liberdade, igualdade na diversidade, saúde sexual e educação sexual do ser humano. Muitas vezes passamos pela vida sem perceber o significado das interferências que todas as dimensões físicas, emocionais, afetivas, espirituais, biológicas, psicológicas e também sexuais têm em nossa existência. 
As questões da dimensão sexualidade ficam muitas vezes à margem das nossas reflexões críticas sobre a vida cotidiana e a declaração recoloca estas questões no universo dos direitos humanos. Desta forma, justifica-se uma introdução a este tema no curso, na qual falaremos dos direitos sexuais relembrando que são direitos humanos já reconhecidos e reafirmados hoje em vários documentos internacionais.

Segundo a declaração citada, os direitos sexuais devem estar contemplados dentro dos direitos humanos fundamentais. Compreende vários direitos entrelaçados entre si e com os direitos humanos como um todo, em um registro com onze direitos, sendo que não existe um mais importante que o outro. Para o pleno exercício da cidadania, é preciso a garantia do conjunto dos Direitos Humanos aí incluídos os direitos sexuais.

Enfim, no último e quarto módulo, abordaremos o direito à educação sexual compreensiva na infância e na adolescência. Para iniciar esse módulo acreditamos ser necessário esclarecer: o que é educação sexual compreensiva. Para responder esta pergunta será importante relembrar o que é educação sexual, discutida no programa 2, e proporcionar aos ouvintes a possibilidade de entender o que significa uma educação sexual compreensiva, segundo o Direito 10 da Declaração, no programa 3: "este é um processo que dura a vida toda desde o nascimento pela vida a fora e deve envolver todas as instituições sociais". (Melo e Pocovi,2002, p.45)

Também trataremos de conversar sobre essa abordagem ser fundamental no cotidiano escolar. Lembraremos que como educadoras e educadores, expressamos sempre nosso posicionamento sobre a temática, percebamos isto ou não, e podemos ajudar (ou não) a formar crianças e adolescentes livres e responsáveis, principalmente por meio de um projeto político pedagógico que pode se propor a ser instrumento de emancipação humana, refletindo-se essa abordagem também na temática educação e sexualidade. Nessa direção o programa 4 tem o objetivo de discutir e esclarecer sobre o direito à educação sexual compreensiva na infância e na adolescência.

\section{Considerações finais}

Com essa proposta de curso pretendemos demonstrar ser importante discutir e esclarecer estes temas também por meio de um curso dentro de um programa de rádio, ferramenta midiática que ainda é de grande alcance, pois faz parte do dia-a-dia de muitas pessoas no Brasil, como já registramos. 
Este caminho que trilhamos nesse projeto, com o uso de tecnologia pensada e produzida para humanos e por humanos, nunca neutra portanto, pode ser percorrido, via este curso, a favor de uma prática educacional apresentada como uma expressão possível de uma ação de formação continuada de educadores e educadoras. Entendida como necessária para apoiar pessoas que atuam seja no cotidiano de uma sala de aula espaço este repleto de acontecimentos e propício a interações que podem ser potencializadas numa perspectiva emancipatória, seja em espaços familiares, contextos por si só educativos em plenitude que também podem ter vivências humanizadoras nessa perspectiva, desde que embasadas em um processo crítico de ação-reflexão-ação. Essa é nossa proposta, mais um desafio para nosso Grupo EDUSEX.

\section{Referências}

FIGUEIRÓ, Mary Neide Damico. Formação de Educadores Sexuais: adiar não é mais possível. 2. ed. Londrina: Eduel, 2014.

KENSKI, Vani Moreira. Educação e tecnologias: novo ritmo da informação. Campinas, SP: Papirus, 2007.

MELO, S. M. M. DE; POCOVI, R. M. DE S; UNIVERSIDADE DO ESTADO DE SANTA CATARINA. Educação e sexualidade: caderno pedagógico I. Florianópolis: CEAD, 2002.

PACHECO, Raquel da Veiga. Escola de princesas: um estudo da compreensão de professoras sobre a influência de filme da boneca Barbie na educação sexual de crianças. 219 p. Dissertação (mestrado) - Universidade do Estado de Santa Catarina, Centro de Ciências Humanas e da Educação, Mestrado em Educação, Florianópolis, $2014 . \quad$ Disponível em: <http://www.tede.udesc.br/tde_busca/arquivo.php?codArquivo=3960>. Acesso em: 15 maio 2016.

\section{Como referenciar este artigo}

FREITAS, Marcia de, et al. Curso de formação de professores (as) por meio do programa educação sexual em debate na rádio UDESC- FM 100.1 Florianópolis: algumas reflexões sobre os caminhos percorridos. Revista Ibero-Americana de Estudos em Educação, Araraquara, v. 12, n. 2, p. 1130-1141, 2017. Disponível em: <http://dx.doi.org/10.21723/riaee.v12.n2.8651>. E-ISSN: 1982-5587. 
Submetido em: 30/05/2016

Aprovado em: 04/04/2017 